\title{
Expert commentary: A multicenter study to define the incidence of short esophagus in surgical patients with gastroesophageal reflux disease
}

\author{
F. Griffith Pearson, MD
}

See related article on page 834.
From the Division of Thoracic Surgery, University of Toronto-Toronto General Hospital, Mansfield, Ontario, Canada.

Received for publication June 16, 2008; accepted for publication June 16, 2008.

Address for reprints: F. Griffith Pearson, MD, University of Toronto-Toronto General Hospital, Surgery-Division of Thoracic Surgery, RR 1, Mansfield, ON L0N 1M0 Canada (E-mail: fgpearson@ sympatico.ca).

J Thorac Cardiovasc Surg 2008;136:842

0022-5223/\$34.00

Copyright $\odot 2008$ by The American Association for Thoracic Surgery

doi:10.1016/j.jtcvs.2008.06.007
I n 1960, during a traveling fellowship in England, I met Jack Leigh Collis in Birmingham. There I was introduced to his original concept of adding a "gastroplasty" to the Collis repair for patients with extreme degrees of peptic esophagitis and stricture. Such advanced cases are rarely encountered today, but in those earlier times, there was no doubt whatsoever that such patients had a significant extent of acquired "short esophagus." Collis used a thoracoabdominal exposure and fashioned a long, 9-cm gastric tube, or gastroplasty, over a 29F bougie. The outcomes though imperfect, were often improved, and this operation avoided the forbidding operative mortality usual in that era after resection and bowel interposition.

I did my first lengthening gastroplasty in 1963, on a frail 70-year-old woman with a long and extreme peptic stricture caused by peptic esophagitis after prolonged postoperative ileus and nasogastric suction. I used a purely transthoracic exposure, fashioned a 5-cm gastric tube over a 50F bougie, and added a Belsey mark IV repair, rather than a Collis repair. The patient survived, and her condition remained much improved for more than a decade thereafter.

I was convinced that short esophagus was a reality, and with subsequent experience recognized lesser and more subtle degrees of short esophagus. These cases were usually associated with some gross endoscopic evidence of peptic esophagitis (past or present) and were seen in patients who also had Barrett's esophagus, in those with massive hiatus hernia, and in a significant number of instances after previous, failed antireflux operations.

As Mattioli and colleagues note in their article, the controversy concerning the incidence (or even the existence) of short esophagus has raged through the subsequent decades. In their prospective, multicenter report, Mattioli and colleagues document the incidence of short esophagus in a consecutive series of surgically treated patients with gastroesophageal reflux disease managed in 7 different centers. The methodology includes a meticulous and detailed technique of preoperative contrast radiographs, with which one of the authors (Mattioli) has had long and well-documented experience. Subsequent intraoperative measurements are obtained with precise and controlled laparoscopic or thoracoscopic measurements. These measurements define the distance between the esophagogastric junction and the apex of the diaphragmatic hiatus (the length of intra-abdominal esophagus in a resting state). The level of the esophagogastric junction is located with intraoperative esophagoscopy.

I find this study the most critical evaluation for acquired short esophagus in any series of surgical patients as yet reported. Despite the extremely effective medication available today for the relief and resolution of peptic esophagitis, there remains a significant incidence of acquired short esophagus among patients selected for operative correction of gastroesophageal reflux disease. 